\title{
A Self-Powered Fast-Response Ultraviolet Detector of p-n Homojunction Assembled from Two ZnO-Based Nanowires
}

\author{
Yumei Wang ${ }^{1,2} \cdot$ Ying Chen $^{1} \cdot$ Wanqiu Zhao ${ }^{1} \cdot$ Longwei Ding $^{1} \cdot$ Li Wen $^{1} \cdot$ Haixia $^{1}{ }^{1} \cdot$ Fan Jiang $^{1}$. \\ Jun $\mathrm{Su}^{1} \cdot$ Luying $\mathrm{Li}^{1} \cdot$ Nishuang $\mathrm{Liu}^{1} \cdot$ Yihua Gao $^{1}$
}

Received: 23 July 2016/Accepted: 10 September 2016/Published online: 5 October 2016

(C) The Author(s) 2016. This article is published with open access at Springerlink.com

\begin{abstract}
Nowadays, fabrication of micro/nano-scale electronic devices with bottom-up approach is paid much research attention. Here, we provide a novel micro/nano-assembling method, which is accurate and efficient, especially suitable for the fabrication of micro/nano-scale electronic devices. Using this method, a self-powered $\mathrm{ZnO} / \mathrm{Sb}$-doped $\mathrm{ZnO}$ nanowire $\mathrm{p}-\mathrm{n}$ homojunction ultraviolet detector (UVD) was fabricated, and the detailed photoelectric properties were tested. At a reverse bias of $-0.1 \mathrm{~V}$ under UV light illumination, the photoresponse sensitivity of the UVD was 26.5 and the rise/decay time of the UVD was as short as $30 \mathrm{~ms}$. The micro/nano-assembling method has wide potential applications in the fabrication of specific micro/nano-scale electronic devices.

Graphical Abstract A self-powered $\mathrm{ZnO} / \mathrm{Sb}$-doped $\mathrm{ZnO}$ nanowire p-n homojunction ultraviolet detector (UVD) was fabricated by using a novel micro/nano-assembling method with bottom-up approach. At reverse bias of $-0.1 \mathrm{~V}$ under UV light illumination, the photoresponse sensitivity of the UVD was 26.5, and the rise time and decay time of the UVD were as short as $30 \mathrm{~ms}$.
\end{abstract}
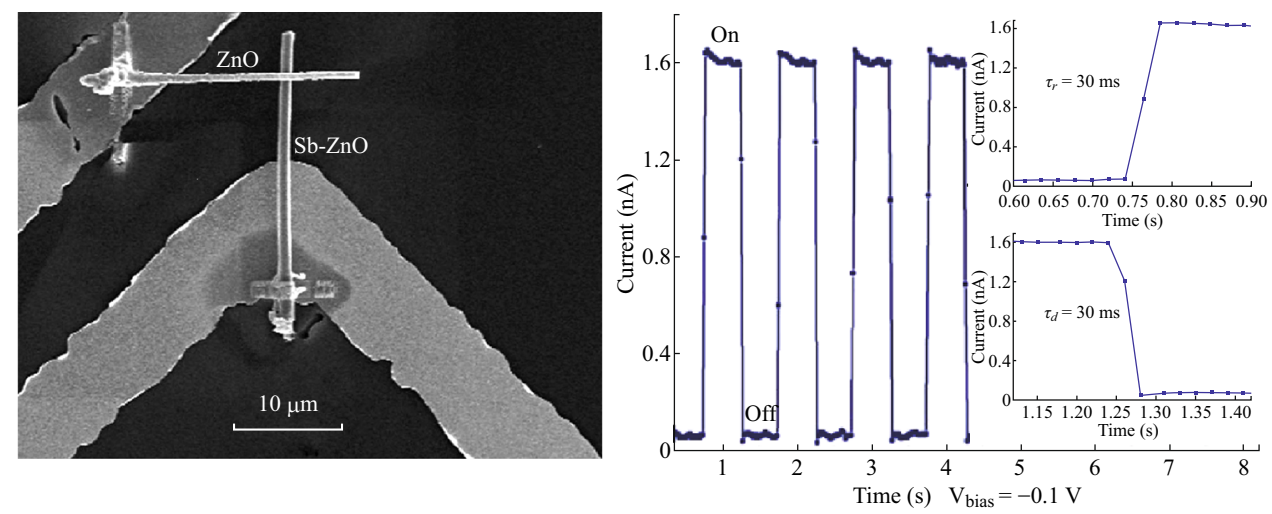

Yumei Wang and Ying Chen have contributed equally to this work.

Yihua Gao

gaoyihua@hust.edu.cn

1 Center for Nanoscale Characterization and Devices (CNCD),

Wuhan National Laboratory for Optoelectronics (WNLO) \&

School of Physics, Huazhong University of Science and

Technology (HUST), Luoyu Road 1037, Wuhan 430074,

People's Republic of China 
Keywords Zinc oxide - Micro/nano-assembling · p-n homojunction · Ultraviolet photodetector

\section{Introduction}

Due to the wide band gap of $3.37 \mathrm{eV}, \mathrm{ZnO}$ has attracted much attention for its potential applications in shortwavelength optoelectronic devices. Compared with another wide-band gap semiconductor of $\mathrm{GaN}, \mathrm{ZnO}$ exhibits a lot of advantages, such as low-temperature synthesis, rich material source, low cost, and environmental friendliness. Since the first $\mathrm{ZnO}$ nanowire (NW) ultraviolet detector (UVD) was fabricated in 2002 [1], a lot of researches related to ZnO UVD have been reported. Generally, there are three types of $\mathrm{ZnO}$ UVDs from the point of view of different working principles: photoconductive UVD, Schottky junction UVD, and $\mathrm{p}-\mathrm{n}$ junction UVD. Photoconductive UVD has a simple structure and a high gain [2-4], but its rise time and decay time are too long [5-10] due to the adsorption and desorption of oxygen molecules. Comparatively, Schottky junction UVD exhibits faster response speed [11, 12]. For example, Wang et al. reported a Schottky junction UVD by utilizing Schottky contact instead of Ohmic contact in device fabrication, and the reset time drastically reduced from $\sim 417$ to $\sim 0.8 \mathrm{~s}$ [13].

$\mathrm{ZnO} \mathrm{p}-\mathrm{n}$ junction UVD, as a self-powered device, has attracted a great deal of research attention due to its fast response speed and high stability which are the unique advantages of $\mathrm{p}-\mathrm{n}$ junction UVD [14-16]. However, the difficulties in fabrication of high-quality p-type $\mathrm{ZnO}$ hinder the applications of ZnO-based p-n junction UVD [17]. Most of $\mathrm{ZnO} \mathrm{p}-\mathrm{n}$ homojunctions are fabricated by two steps: growth of n-type $\mathrm{ZnO} \mathrm{NW}$ section and p-type $\mathrm{ZnO} \mathrm{NW}$ section [18-20]. Formation of $\mathrm{ZnO} \mathrm{p}-\mathrm{n}$ homojunction is much difficult due to the p-type doping difficulty of $\mathrm{ZnO}$. Nevertheless, it is relatively easier to synthesize n-type $\mathrm{ZnO}$ and p-type $\mathrm{ZnO} \mathrm{NWs}$ separately. Intrinsic $\mathrm{ZnO}$ has n-type conductivity, and group $\mathrm{V}$ elements are often used to form p-type doping of $\mathrm{ZnO}$, such as nitrogen [21], phosphorus [20], arsenic [22], and antimony (Sb) [23-26]. Along with the development of micro/nano-assembling techniques, bottom-up fabrication of micro/nano-scale electronic devices comes true.

In this work, we demonstrate an efficient method to fabricate a self-powered $\mathrm{ZnO} \mathrm{p}-\mathrm{n}$ homojunction UVD, and high sensitivity and ultra-fast photoresponse speed were obtained. At a reverse bias of $-0.1 \mathrm{~V}$ under UV light illumination, the $\mathrm{ZnO} \mathrm{p}-\mathrm{n}$ homojunction UVD has a sensitivity of 26.5, and the rise time $\tau_{\mathrm{r}}(10-90 \%)$ and decay time $\tau_{\mathrm{d}}(90-10 \%)$ of $30 \mathrm{~ms}$. The size of UVD is very small and it can be integrated into a single chip to realize multifunction device. Our work presents an efficient and accurate way to build micro/nano-scale electronic devices with high performances.

\section{Experimental Section}

\subsection{Synthesis of $\mathrm{ZnO} \mathrm{NWs}$ and Sb-Doped $\mathrm{ZnO}$ (Sb- ZnO) NWs}

Two NWs of $\mathrm{ZnO}$ and $\mathrm{Sb}-\mathrm{ZnO}$ were synthesized via a simple chemical vapor deposition (CVD) method in a horizontal quartz tube furnace. A mixture of high-purity powders (weight ratio of $\mathrm{ZnO}$ :graphite $=1: 1$ for $\mathrm{ZnO} \mathrm{NWs}$; molar ratio of $\mathrm{Zn}: \mathrm{Sb}_{2} \mathrm{O}_{3}$ :graphite = 4:1:2 for $\mathrm{Sb}-\mathrm{ZnO}$ NWs [24]) were used as the raw materials. For $\mathrm{ZnO} N W s$, Au film with 3-5 nm thickness was firstly deposited on the Si substrate by a sputtering deposition method. In the growth process of $\mathrm{ZnO}$, a mixed gas of $100 \mathrm{sccm} \mathrm{Ar}$ and $5 \mathrm{sccm} \mathrm{O} \mathrm{O}_{2}$ was used as the carrier gas and oxygen source, whereas $200 \mathrm{sccm} \mathrm{Ar}$ and $8 \mathrm{sccm} \mathrm{O} \mathrm{O}_{2}$ were used in the fabrication process of $\mathrm{Sb}-\mathrm{ZnO}$ NWs. For ZnO NWs, the chamber was heated to $950{ }^{\circ} \mathrm{C}$ at a rate of $50{ }^{\circ} \mathrm{C} \mathrm{min}^{-1}$ and lasted 40 min under 1 atm pressure, whereas it was heated to $930{ }^{\circ} \mathrm{C}$ and lasted $50 \mathrm{~min}$ for $\mathrm{Sb}-$ $\mathrm{ZnO}$ NWs. Then, the furnace was cooled down to room temperature naturally.

\subsection{Device Fabrication and Characterization}

The Au/Ti electrodes with $10 \mu \mathrm{m}$ finger spacing were fabricated by optical lithography and lift-off process on oxidized $\mathrm{Si}$ substrate (300-nm $\mathrm{SiO}_{2}$ ). The thicknesses of $\mathrm{Au}$ and Ti layers are 50 and $10 \mathrm{~nm}$, respectively. The micro/nanoassembling process was performed in a dual-beam scanning electron microscope (SEM)/focused ion beam (FIB) microscope (FEI Quanta 3D FEG) equipped with nanomanipulator (Oxford Instruments OmniProbe 100) and gas injection system (GIS), and therefore the whole operating process can be monitored in real time. Firstly, one ZnO NW with suitable width and length was selected, and the tip of the nanomanipulator was handled carefully to make the tip contact with one side of the $\mathrm{ZnO} N W$ lightly. Secondly, the tip of the nanomanipulator and the $\mathrm{ZnO} \mathrm{NW}$ were welded together by direct-written Pt deposition. Thirdly, the other side of the $\mathrm{ZnO}$ NW was cut off by the FIB. Finally, the $\mathrm{ZnO}$ NW was extracted and transferred it to anywhere we want.

The $\mathrm{ZnO} \mathrm{NW}$ and another $\mathrm{Sb}-\mathrm{ZnO} \mathrm{NW}$ were transferred to the electrodes on chip. It is necessary to make one side of $\mathrm{Sb}-\mathrm{ZnO} \mathrm{NW}$ contact with the $\mathrm{ZnO} \mathrm{NW}$ transferred before. The other sides of $\mathrm{Sb}-\mathrm{ZnO} \mathrm{NW}$ and intrinsic $\mathrm{ZnO}$ 
NW were welded on the Au electrodes by direct-written Pt deposition. Care was taken to avoid any contamination on the NWs' surface on the chip.

The morphology, crystalline structure, and element distribution of the as-synthesized samples are characterized by SEM (FEI Nova Nano-SEM 450) and high-resolution transmission electron microscope (HRTEM, FEI Titan G2 60-300). The $I-V$ characteristics and photoresponse of the devices were measured using an Agilent B2901A with the time resolution of $20 \mu \mathrm{s}$, a portable UV $\operatorname{lamp}(\lambda=365 \mathrm{~nm}$, $0.3 \mathrm{~mW} \mathrm{~cm}^{-2}$ ), and a function generator. All the electrical properties and photoelectric properties were tested at room temperature under atmospheric condition.

\section{Results and Discussion}

$\mathrm{ZnO} \mathrm{NWs}$ and $\mathrm{Sb}-\mathrm{ZnO} \mathrm{NWs}$ were synthesized through a conventional CVD method. Sb-ZnO NWs have p-type characteristics due to the formation of $\mathrm{Sb}_{\mathrm{Zn}}-2 \mathrm{~V}_{\mathrm{Zn}}$ complex acceptor [23-26]. Typical SEM images of $\mathrm{ZnO}$ and $\mathrm{Sb}-$ $\mathrm{ZnO}$ NWs are shown in Fig. 1a, b. The $\mathrm{ZnO}$ and $\mathrm{Sb}-\mathrm{ZnO}$ NWs are several micrometers in length, and $50 \mathrm{~nm}$ to $10 \mu \mathrm{m}$ in diameter. The EDS spectrum (Fig. 1d) shows that the synthesized $\mathrm{Sb}-\mathrm{ZnO} \mathrm{NW}$ are composed of $\mathrm{O}, \mathrm{Zn}$, and $\mathrm{Sb}$ elements. The content of $\mathrm{Sb}$ was estimated to be approximately $3 \%$ (atom ratio). Figure 1c shows the elemental mapping images of $\mathrm{Sb}-\mathrm{ZnO} \mathrm{NW}$, which reveals that the $\mathrm{Sb}$ element was doped into the $\mathrm{ZnO} \mathrm{NWs}$ successfully and distributed uniformly. HRTEM images (Fig. 1e, f) of individual $\mathrm{ZnO}$ and $\mathrm{Sb}-\mathrm{ZnO} \mathrm{NWs}$ show clear lattice fringes, indicating that both of the NWs exhibit single-crystal structures and grow along the [0001] direction. However, the surface of $\mathrm{Sb}-\mathrm{ZnO} \mathrm{NW}$ is a rough amorphous layer (Fig. 1f). This phenomenon may be caused by the introduction of $\mathrm{Sb}^{3+}$ ion (radius $0.078 \mathrm{~nm}$ ) that is larger than $\mathrm{Zn}^{2+}(0.074 \mathrm{~nm})$, which leads to a large structural strain released by the rough surface [27].

The $\mathrm{ZnO} / \mathrm{Sb}-\mathrm{ZnO} \mathrm{p}-\mathrm{n}$ homojunctions were fabricated in a dual-beam SEM/FIB microscope. Direct-written $\mathrm{Pt}$ deposition by FIB was used to prepare Pt electrodes. Even though the work function of $\mathrm{Pt}(\sim 6.1 \mathrm{eV})$ is higher than that of pure $\mathrm{ZnO}(\sim 5.1 \mathrm{eV})$, the contact electrodes of $\mathrm{ZnO} / \mathrm{Pt}$ fabricated by $\mathrm{Ga}$ ion surface modification process and direct-written Pt deposition could still be Ohmic [28]. Figure $2 \mathrm{c}$ shows the $I-V$ characteristics of the $\mathrm{ZnO} \mathrm{NW}$ and $\mathrm{Sb}-\mathrm{ZnO} \mathrm{NW}$. One can notice that both the $I-V$ curves are linear, indicating good Ohmic contacts between $\mathrm{ZnO}$ (or $\mathrm{Sb}-\mathrm{ZnO}$ ) and $\mathrm{Pt}$ electrodes. The $\mathrm{Sb}-\mathrm{ZnO} \mathrm{NW}$ exhibits better conductivity than pure $\mathrm{ZnO} \mathrm{NW}$.

The fabrication processes of $\mathrm{ZnO} / \mathrm{Sb}-\mathrm{ZnO} \mathrm{p}-\mathrm{n}$ homojunction are schematically shown in Fig. 2a, b. The Ohmic $\mathrm{ZnO} / \mathrm{Pt}$ contact and $\mathrm{Sb}-\mathrm{ZnO} / \mathrm{Pt}$ contact were made carefully by the same processes described above. The inset of Fig. 2d shows the SEM image of the device, where the $\mathrm{ZnO} \mathrm{NW}$ and $\mathrm{Sb}-\mathrm{ZnO} \mathrm{NW}$ are connected. The $\mathrm{ZnO}$ and $\mathrm{Sb}-\mathrm{ZnO} \mathrm{NWs}$ have the diameters of $\sim 500 \mathrm{~nm}$ and the lengths of $\sim 20 \mu \mathrm{m}$. The $I-V$ curve (Fig. $2 \mathrm{~d}$ ) of $\mathrm{ZnO} / \mathrm{Sb}-$ $\mathrm{ZnO} \mathrm{p}-\mathrm{n}$ homojunction displays significant rectification characteristics under dark condition. The rectification ratio of the $\mathrm{ZnO} \mathrm{p}-\mathrm{n}$ homojunction diode is about $3.3 \times 10^{2}$ at $\pm 1 \mathrm{~V}$, and the turn-on voltage is $\sim 1 \mathrm{~V}$.

To investigate the photoelectric properties, the $I-$ $V$ characteristics of the $\mathrm{ZnO} / \mathrm{Sb}-\mathrm{ZnO} \mathrm{p}-\mathrm{n}$ homojunction were measured both in dark and upon $365 \mathrm{~nm}$ UV light illumination, as shown in Fig. 3a. The distance between the UV light and the device is fixed, and the power density of the UV light is about $0.3 \mathrm{~mW} \mathrm{~cm}^{-2}$. The UVD is responsive to the UV light significantly especially at reverse bias, which agrees with the behavior of the $\mathrm{p}-\mathrm{n}$ junction photodetector. Figure 3b, c shows the energy band diagram of the $\mathrm{p}-\mathrm{n}$ junction in dark and under UV light illumination at reverse bias, where the width of depletion layer and the barrier height will increase and weaken the dark current. When the contact area of $\mathrm{ZnO}$ and $\mathrm{Sb}-\mathrm{ZnO}$ NW is exposed to UV light, the reverse bias will enhance the built-in electric field of the $\mathrm{p}-\mathrm{n}$ junction. The photoinduced electrons and holes in the depletion layer will be swept away to the opposite direction quickly by the strong electric field, which will cause a large increase in photocurrent.

Figure $4 \mathrm{a}, \mathrm{b}$ shows the photoresponse of the UVD as a function of time when the UV illumination was switched on and off periodically, where the UV light was controlled by a function generator. At zero-voltage bias, the UVD worked as a self-powered device, and the open-circuit voltage $V_{\text {oc }}$ is $\sim 9 \mathrm{mV}$ under $\mathrm{UV}$ light illumination. At a reverse bias of $-0.1 \mathrm{~V}$, the dark current is $60 \mathrm{pA}$ and the photocurrent is $1.65 \mathrm{nA}$ under $\mathrm{UV}$ light illumination. The sensitivity (defined as $\left.\left(I_{\text {light }}-I_{\text {dark }}\right) / I_{\text {dark }}\right)$ of the UVD is about 26.5. Both the voltage-time curve and the currenttime curve show the stable and repetitive on/off cycles without significant noise. The $\mathrm{ZnO} / \mathrm{Sb}-\mathrm{ZnO} \mathrm{p}-\mathrm{n}$ junction UVD can work properly without external bias, which decreases the energy consumption or exhibits high sensitivity at certain reverse bias.

Fast response speed is one of the outstanding advantages of $\mathrm{p}-\mathrm{n}$ junction UVD. Figure 5 shows the enlarged current-time curve of the UVD at a reverse bias of $-0.1 \mathrm{~V}$ with $365 \mathrm{~nm}$ UV light illumination. The rise time $\tau_{\mathrm{r}}$ $(10-90 \%)$ and decay time $\tau_{\mathrm{d}}(90-10 \%)$ are estimated to be $30 \mathrm{~ms}$, which are even shorter than those of the asgrown $\mathrm{ZnO}$ p-n homojunction UVDs [14, 29] and Schottky junction UVDs [11, 12, 30-32]. The fast-response mechanism is attributed to the $\mathrm{p}-\mathrm{n}$ junction formed between $\mathrm{ZnO}$ and $\mathrm{Sb}-\mathrm{ZnO} \mathrm{NWs}$, rather than the $\mathrm{ZnO} \mathrm{NW}$ or $\mathrm{Sb}-$ 

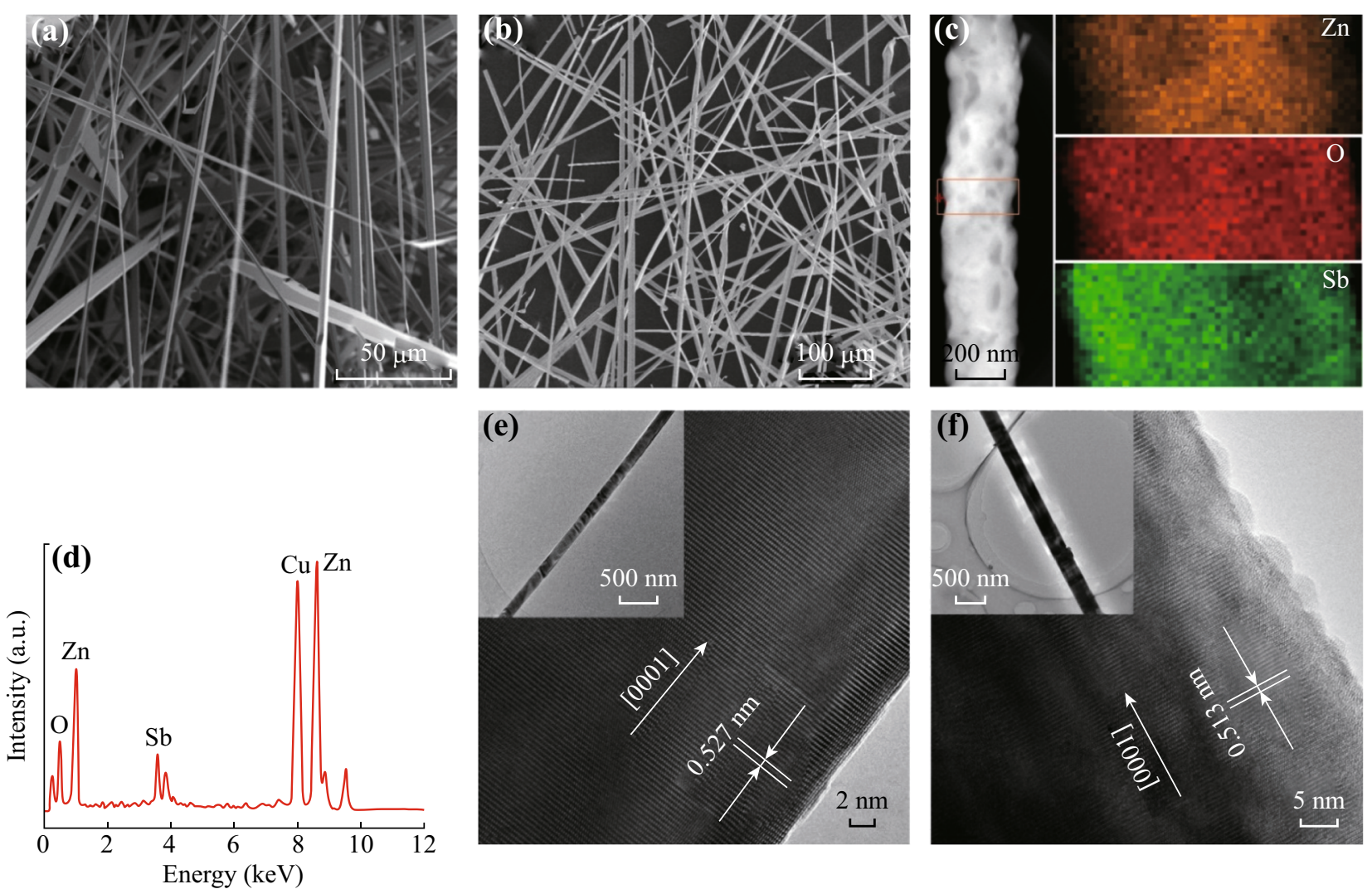

Fig. 1 Characterization of $\mathrm{ZnO}$ and $\mathrm{Sb}-\mathrm{ZnO}$ NWs. SEM images of $\mathbf{a} \mathrm{ZnO}$ and $\mathbf{b} \mathrm{Sb}-\mathrm{ZnO}$ NWs. $\mathbf{c}$ EDS mapping images and $\mathbf{d}$ EDS spectrum of $\mathrm{Sb}-\mathrm{ZnO} \mathrm{NW}$. TEM and HRTEM images of e ZnO NW and $\mathbf{f} \mathrm{Sb}-\mathrm{ZnO} \mathrm{NW}$

(a)

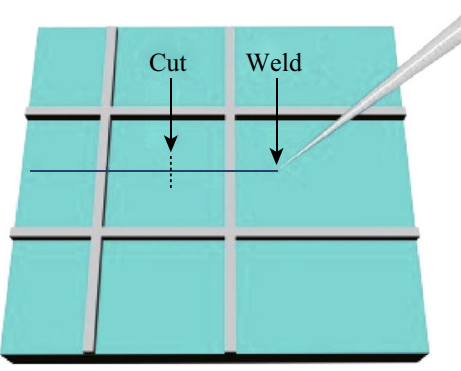

(c)

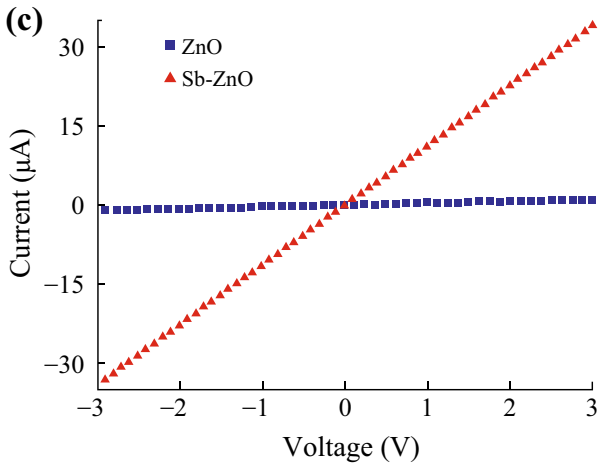

(b)
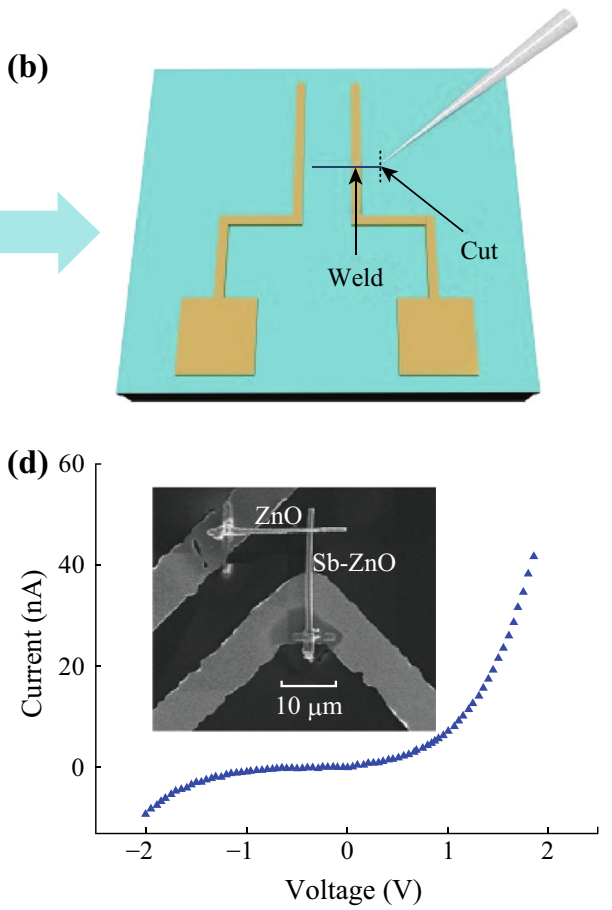

Fig. 2 a and b Schematic diagrams showing the procedure of micro/nano-assembling. $\mathbf{c} I-V$ characteristics of a pure $\mathrm{ZnO} \mathrm{NW}$ and a $\mathrm{Sb}-\mathrm{ZnO}$ $\mathrm{NW}$. The linear $I-V$ curves indicate well Ohmic contacts. d $I-V$ characteristics of p-type $\mathrm{Sb}-\mathrm{ZnO} / \mathrm{n}$-type $\mathrm{ZnO}$ homojunction in dark. The inset SEM image in $\mathbf{d}$ shows the device structure 


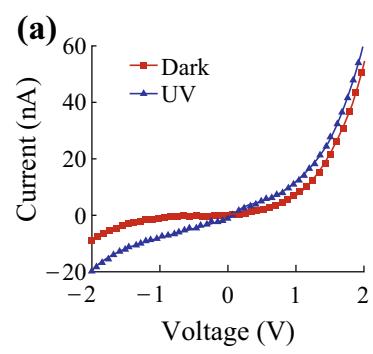

(b)

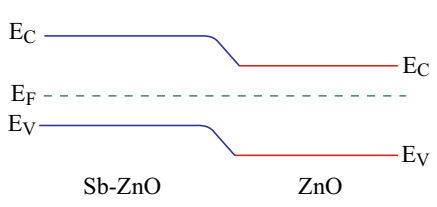

(c)

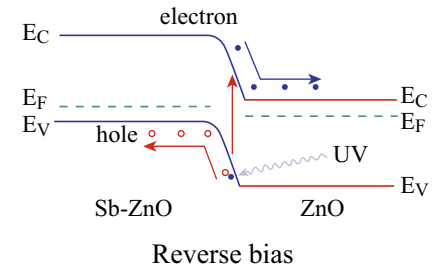

Fig. 3 a $I-V$ curves of $\mathrm{ZnO} / \mathrm{Sb}-\mathrm{ZnO} \mathrm{p}-\mathrm{n}$ homojunction in dark (red) and under $365 \mathrm{~nm}$ UV light illumination (blue). The energy band diagram of the $\mathrm{p}-\mathrm{n}$ homojunction in $\mathbf{b}$ dark and under $\mathbf{c} \mathrm{UV}$ light illumination at reverse bias

(a)

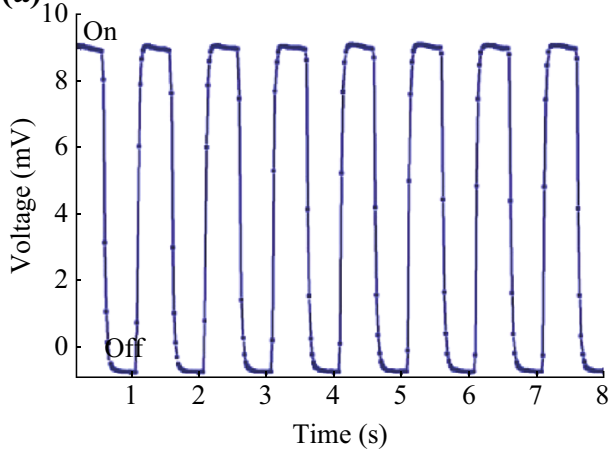

(b)

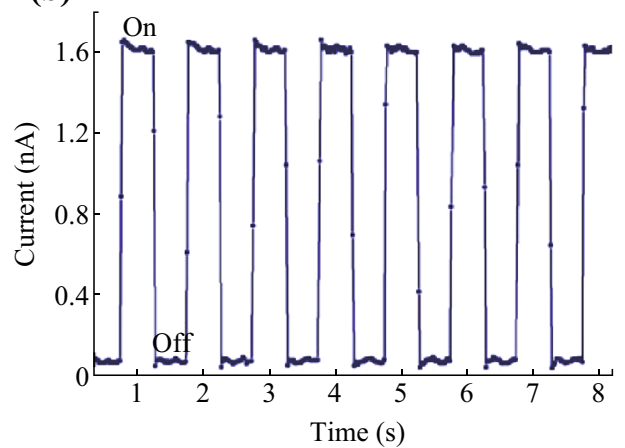

Fig. 4 a Voltage-time curve of the p-n junction UVD at $0 \mathrm{~V}$ bias with $365 \mathrm{~nm}$ UV light on and off. b Current-time curve of the p-n junction UVD at a reverse bias of $-0.1 \mathrm{~V}$ with $365 \mathrm{~nm}$ UV light on and off

(a)

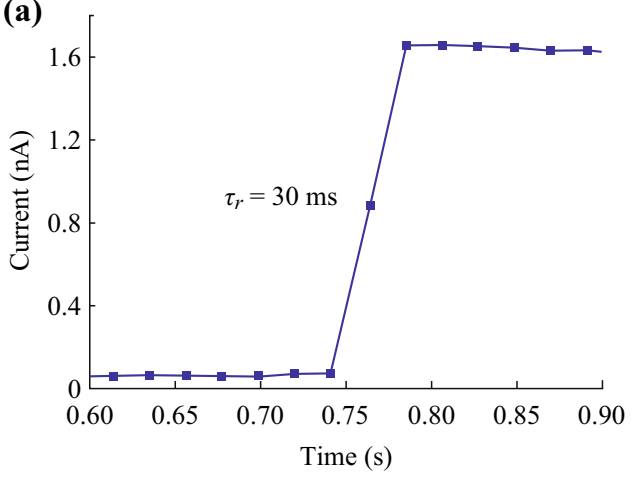

(b)

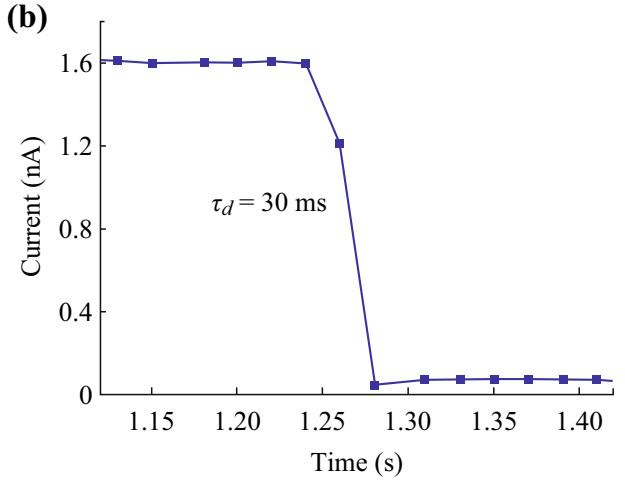

Fig. 5 Enlarged current-time curves of the UVD of a the rise time and $\mathbf{b}$ the decay time, which were estimated to be $30 \mathrm{~ms}$

$\mathrm{ZnO}$ NW photoconductor. The fast photoresponse performance is very stable and reproducible even in atmosphere environment.

Photoresponse of the UVD at different reverse bias from -1.0 to $0 \mathrm{~V}$ was also investigated. Figure $6 \mathrm{a}$ shows the current-time curves of the $\mathrm{p}-\mathrm{n}$ junction UVD at different reverse bias with the $365 \mathrm{~nm}$ UV light on and off periodically. At zero-voltage bias, the short-circuit current $I_{\mathrm{sc}}$ is $\sim 0.5 \mathrm{nA}$. The UVD works stable and reliable at different reverse bias, which implies wide potential applications. The photoresponse sensitivity of this UVD as a function of the applied reverse bias is shown in Fig. 6b. When higher extra reverse bias is applied, the dark current increases and the sensitivity decreases, which may be caused by the increasing leakage current.

The $\mathrm{ZnO} / \mathrm{Sb}-\mathrm{ZnO} \mathrm{p}-\mathrm{n}$ junction could be used as a UVD with fast response performance and high stability, or as a nano-scale photovoltaic cell. The micro/nano-assembling method has been proved to be an efficient and accurate way to build high-performance micro/nano-scale $p-n$ junction UVD. The open-circuit voltage was improved using n-type $\mathrm{ZnO}$ and p-type $\mathrm{ZnO}$ with higher doping density, and it is 

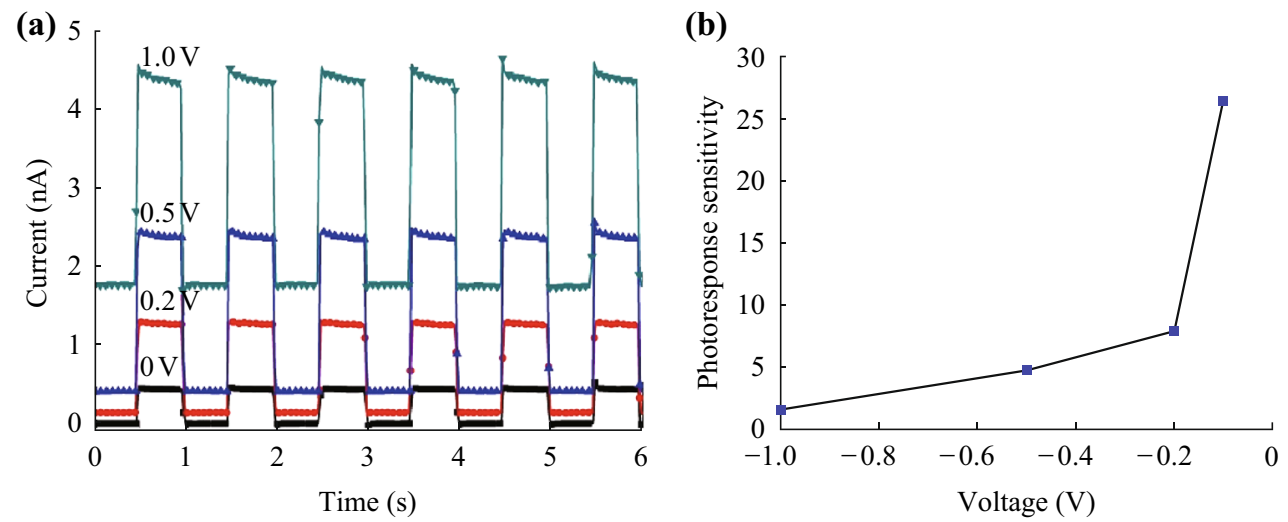

Fig. 6 a Current-time curves of the $\mathrm{p}-\mathrm{n}$ junction UVD at different reverse bias from -1.0 to $0 \mathrm{~V}$ with the $365 \mathrm{~nm}$ UV light on and off. b Photoresponse sensitivity of this UVD as a function of the applied reverse bias

much easier to control the doping density when the two kinds of NWs are synthesized separately. Moreover, with the help of the micro/nano-assembling method, we can freely combine semiconductor nanomaterials with different band gaps to build $\mathrm{p}-\mathrm{n}$ junction photodetectors, which can be responsive to light of different wavelength ranges.

\section{Conclusion}

In conclusion, we fabricated a $\mathrm{ZnO} / \mathrm{Sb}-\mathrm{ZnO} \mathrm{p}-\mathrm{n}$ junction UVD by a micro/nano-assembling method. The self-powered UVD exhibits high sensitivity and stability, and the rise time and decay time reach $30 \mathrm{~ms}$. This micro/nanoassembling method provides an efficient and accurate way to fabricate micro/nano-scale electronic devices with potential applications.

Acknowledgments This work was supported by the National Natural Science Foundation of China (11374110, 51371085, 11304106). Y.H.G would like to thank Prof. Zhong Lin Wang for the support of experimental facilities in WNLO of HUST.

Open Access This article is distributed under the terms of the Creative Commons Attribution 4.0 International License (http://crea tivecommons.org/licenses/by/4.0/), which permits unrestricted use, distribution, and reproduction in any medium, provided you give appropriate credit to the original author(s) and the source, provide a link to the Creative Commons license, and indicate if changes were made.

\section{References}

1. H. Kind, H.Q. Yan, B. Messer, M. Law, P.D. Yang, Nanowire ultraviolet photodetectors and optical switches. Adv. Mater. 14(2), 158-160 (2002). doi:10.1002/1521-4095(20020116)14: $2<158$ :Aid-Adma158>3.0.Co;2-W

2. C. Soci, A. Zhang, B. Xiang, S.A. Dayeh, D.P. Aplin, J. Park, X.Y. Bao, Y.H. Lo, D. Wang, ZnO nanowire UV photodetectors with high internal gain. Nano Lett. 7(4), 1003-1009 (2007). doi:10.1021/n1070111x

3. Z. Zhang, Q. Liao, Y. Yu, X. Wang, Y. Zhang, Enhanced photoresponse of $\mathrm{ZnO}$ nanorods-based self-powered photodetector by piezotronic interface engineering. Nano Energy 9, 237-244 (2014). doi:10.1016/j.nanoen.2014.07.019

4. Y. Liu, X. Zhang, J. Su, H. Li, Q. Zhang, Y. Gao, Ag nanoparticles@ZnO nanowire composite arrays: an absorption enhanced UV photodetector. Opt. Express 22(24), 30148-30155 (2014). doi:10.1364/OE.22.030148

5. Y. Hao, J. Zhao, L. Qin, Q. Guo, X. Feng, P. Wang, Facile fabrication of UV photodetector based on spatial network of tetrapod ZnO nanostructures. Nano-Micro Lett. 7(3), 200-203 (2012). doi:10.1049/mnl.2011.0721

6. Y. Li, C. Cheng, X. Dong, J. Gao, H. Zhang, Facile fabrication of UV photodetectors based on $\mathrm{ZnO}$ nanorod networks across trenched electrodes. J. Semicond. 30(6), 38-41 (2009). doi:10. 1088/1674-4926/30/6/063004

7. S.E. Ahn, H.J. Ji, K. Kim, G.T. Kim, C.H. Bae, S.M. Park, Y.K. Kim, J.S. Ha, Origin of the slow photoresponse in an individual sol-gel synthesized $\mathrm{ZnO}$ nanowire. Appl. Phys. Lett. 90(15), 153106 (2007). doi:10.1063/1.2721289

8. J. Cheng, Y. Zhang, R. Guo, ZnO microtube ultraviolet detectors. J. Cryst. Growth 310(1), 57-61 (2008). doi:10.1016/j.jcrysgro. 2007.08.034

9. S.E. Ahn, J.S. Lee, H. Kim, S. Kim, B.H. Kang, K.H. Kim, G.T. Kim, Photoresponse of sol-gel-synthesized $\mathrm{ZnO}$ nanorods. Appl. Phys. Lett. 84(24), 5022 (2004). doi:10.1063/1.1763633

10. X. Zhang, X. Han, J. Su, Q. Zhang, Y. Gao, Well vertically aligned $\mathrm{ZnO}$ nanowire arrays with an ultra-fast recovery time for UV photodetector. Appl. Phys. A 107(2), 255-260 (2012). doi:10. 1007/s00339-012-6886-6

11. Y. Hu, J. Zhou, P.H. Yeh, Z. Li, T.Y. Wei, Z.L. Wang, Supersensitive, fast-response nanowire sensors by using Schottky contacts. Adv. Mater. 22(30), 3327-3332 (2010). doi:10.1002/ adma.201000278

12. Y. Yang, W. Guo, J. Qi, J. Zhao, Y. Zhang, Self-powered ultraviolet photodetector based on a single Sb-doped $\mathrm{ZnO}$ nanobelt. Appl. Phys. Lett. 97(22), 223113 (2010). doi:10.1063/1. 3524231

13. J. Zhou, Y. Gu, Y. Hu, W. Mai, P.H. Yeh, G. Bao, A.K. Sood, D.L. Polla, Z.L. Wang, Gigantic enhancement in response and reset time of ZnO UV nanosensor by utilizing Schottky contact and surface functionalization. Appl. Phys. Lett. 94(19), 191103 (2009). doi:10.1063/1.3133358 
14. H.D. Cho, A.S. Zakirov, S.U. Yuldashev, C.W. Ahn, Y.K. Yeo, T.W. Kang, Photovoltaic device on a single $\mathrm{ZnO}$ nanowire $\mathrm{p}-\mathrm{n}$ homojunction. Nanotechnology 23(11), 115401 (2012). doi:10. 1088/0957-4484/23/11/115401

15. Y.Q. Bie, Z.M. Liao, H.Z. Zhang, G.R. Li, Y. Ye et al., Selfpowered, ultrafast, visible-blind UV detection and optical logical operation based on $\mathrm{ZnO} / \mathrm{GaN}$ nanoscale p-n junctions. Adv. Mater. 23(5), 649-653 (2011). doi:10.1002/adma.201003156

16. Y.Q. Bie, Z.M. Liao, P.W. Wang, Y.B. Zhou, X.B. Han et al., Single $\mathrm{ZnO}$ nanowire/p-type GaN heterojunctions for photovoltaic devices and UV light-emitting diodes. Adv. Mater. 22(38), 4284-4287 (2010). doi:10.1002/adma.201000985

17. C.H. Park, S.B. Zhang, S.H. Wei, Origin of p-type doping difficulty in $\mathrm{ZnO}$ : the impurity perspective. Phys. Rev. B 66(7), 073202 (2002). doi:10.1103/PhysRevB.66.073202

18. G. Li, A. Sundararajan, A. Mouti, Y.J. Chang, A.R. Lupini, S.J. Pennycook, D.R. Strachan, B.S. Guiton, Synthesis and characterization of p-n homojunction-containing zinc oxide nanowires. Nanoscale 5(6), 2259-2263 (2013). doi:10.1039/c3nr31639d

19. C.L. Hsu, Y.D. Gao, Y.S. Chen, T.J. Hsueh, Vertical p-type Cudoped $\mathrm{ZnO} / \mathrm{n}$-type $\mathrm{ZnO}$ homojunction nanowire-based ultraviolet photodetector by the furnace system with hotwire assistance. ACS Appl. Mater. Interfaces 6(6), 4277-4285 (2014). doi:10. 1021/am406030d

20. M.T. Chen, M.P. Lu, Y.J. Wu, J. Song, C.Y. Lee et al., Near UV LEDs made with in situ doped $\mathrm{p}$-n homojunction $\mathrm{ZnO}$ nanowire arrays. Nano Lett. 10(11), 4387-4393 (2010). doi:10.1021/ nl101907h

21. B. Chavillon, L. Cario, A. Renaud, F. Tessier, F. Chevire et al., P-type nitrogen-doped $\mathrm{ZnO}$ nanoparticles stable under ambient conditions. J. Am. Chem. Soc. 134(1), 464-470 (2012). doi:10. 1021/ja208044k

22. J.Y. Zhang, P.J. Li, H. Sun, X. Shen, T.S. Deng, K.T. Zhu, Q.F. Zhang, J.L. Wu, Ultraviolet electroluminescence from controlled arsenic-doped $\mathrm{ZnO}$ nanowire homojunctions. Appl. Phys. Lett. 93(2), 021116 (2008). doi:10.1063/1.2958230

23. X. Ren, X. Zhang, N. Liu, L. Wen, L. Ding et al., White lightemitting diode from $\mathrm{Sb}$-doped $\mathrm{p}-\mathrm{ZnO}$ nanowire Arrays $/ \mathrm{n}-\mathrm{GaN}$ film. Adv. Funct. Mater. 25(14), 2182-2188 (2015). doi:10.1002/ adfm. 201404316
24. Y. Yang, K.C. Pradel, Q.S. Jing, J.M. Wu, F. Zhang, Y.S. Zhou, Y. Zhang, Z.L. Wang, Thermoelectric nanogenerators based on single Sb-doped $\mathrm{ZnO}$ micro/nanobelts. ACS Nano 6(8), 6984-6989 (2012). doi:10.1021/Nn302481p

25. W. Chen, J. Wu, J. Lin, S. Lo, H. Lin, D. Hang, M. Shih, C Liang, Y. Chang, Room temperature violet luminescence and ultraviolet photodetection of Sb-doped $\mathrm{ZnO} / \mathrm{Al}$-doped $\mathrm{ZnO}$ homojunction array. Nanoscale Res. Lett. 8(1), 313 (2013). doi:10.1186/1556-276X-8-313

26. L. Shi, F. Wang, B. Li, X. Chen, B. Yao, D. Zhao, D. Shena, A highly efficient $\mathrm{UV}$ photodetector based on a $\mathrm{ZnO}$ microwire $\mathrm{p}-\mathrm{n}$ homojunction. J. Mater. Chem. C 2, 5005-5010 (2014). doi:10. 1039/c3tc32547d

27. Y. Yang, J.J. Qi, Q.L. Liao, Y. Zhang, L.D. Tang, Z. Qin, Synthesis and characterization of Sb-Doped $\mathrm{ZnO}$ nanobelts with single-side Zigzag boundaries. J. Phys. Chem. C 112(46), 17916-17919 (2008). doi:10.1021/jp8064213

28. J.H. He, J.J. Ke, P.H. Chang, K.T. Tsai, P.C. Yang, I.M. Chan, Development of Ohmic nanocontacts via surface modification for nanowire-based electronic and optoelectronic devices: $\mathrm{ZnO}$ nanowires as an example. Nanoscale 4(11), 3399-3404 (2012). doi:10.1039/c2nr30688c

29. J. Qi, X. Hu, Z. Wang, X. Li, W. Liu, Y. Zhang, A self-powered ultraviolet detector based on a single $\mathrm{ZnO}$ microwire/p-Si film with double heterojunctions. Nanoscale 6(11), 6025-6029 (2014). doi:10.1039/c3nr06356a

30. Y. Li, A. Paulsen, I. Yamada, Y. Koide, J.J. Delaunay, Bascule nanobridges self-assembled with $\mathrm{ZnO}$ nanowires as double Schottky barrier UV switches. Nanotechnology 21(29), 295502 (2010). doi:10.1088/0957-4484/21/29/295502

31. G. Cheng, X. Wu, B. Liu, B. Li, X. Zhang, Z. Du, ZnO nanowire Schottky barrier ultraviolet photodetector with high sensitivity and fast recovery speed. Appl. Phys. Lett. 99(20), 203105 (2011). doi: $10.1063 / 1.3660580$

32. X. Fu, Z. Liao, Y. Zhou, H. Wu, Y. Bie, J. Xu, D. Yu, Graphene/ $\mathrm{ZnO}$ nanowire/graphene vertical structure based fast-response ultraviolet photodetector. Appl. Phys. Lett. 100(22), 223114 (2012). doi:10.1063/1.4724208 